\title{
Canadian prisoner health complaints system better than that in United States, but still spotty
}

$\mathrm{T}$ hough the system for handling health care complaints from prisoners in the Canadian correctional system is far from perfect, inmates are free to raise as many concerns as they like. Prisoners in the United States can also complain, though they have to go to much greater lengths to be heard.

"Most prisoner complaints [in the US] about health care are sort of specific to the individual prisoner; a prisoner is unhappy with the care he's receiving for a particular condition, or he or she runs out of medication. A lot of times the complaints are sort of to no avail unfortunately," says Gabe Eber, a spokesperson for the American Civil Liberties Union National Prison Project.

Eber says that because of the Prison Litigation Reform Act, a US federal law enacted in 1996 that aimed to decrease the amount of prisoner hearings in the court system, the practice of processing and appealing complaints has become very adversarial and can take months to complete in certain cases.

"In general you've got to pry pretty deep in order to get records of prisoner complaints. In my experience, usually the grievance systems are just kind of for show and don't really resolve anything. So it's pretty difficult to get data based on prisoner complaints," says Eber.

"There's a lot of prisoner litigation in federal courts about medical issues but it's almost impossible to succeed on your own representing yourself and prisoners generally can't afford lawyers to represent them."

By comparison, complaints related to specific health care providers or medical issues in Canadian institutions generally move through three channels: the Office of the Correctional Investigator, the Colleges of Physicians and Surgeons and internally through individual prisons.

The majority of complaints in the Canadian federal correctional system

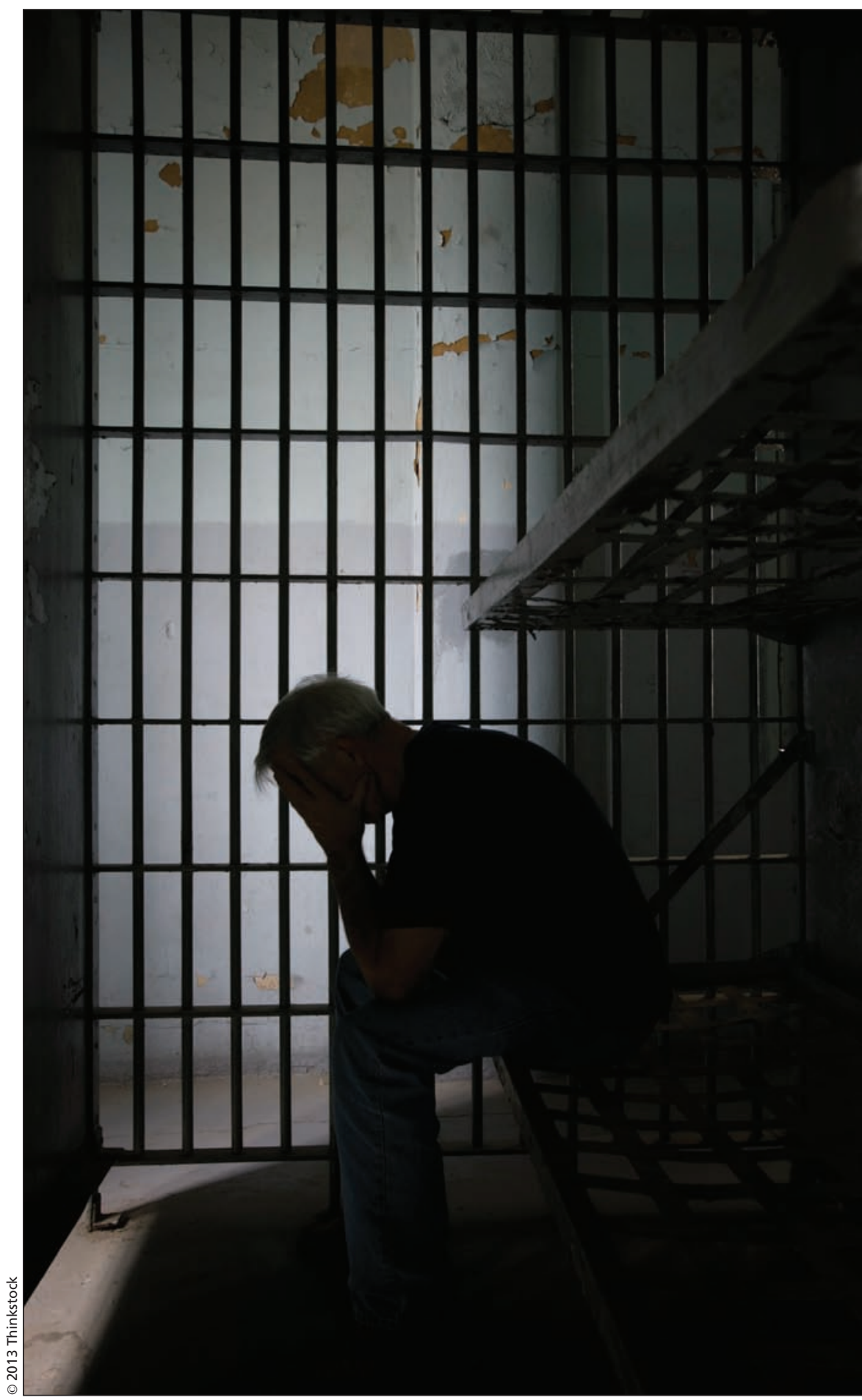

Inmates in US prisons are likely to grow frustrated if they take issue with the medical care they receive because processing and appealing complaints tends to take a long time, according to the American Civil Liberties Union National Prison Project. 
go through the Office of the Correctional Investigator, a micro-agency with 32 employees.

"We've seen cases where colleges have provided discipline to both physicians and nurses from time to time, but again it's not frequent," says Howard Sapers, correctional investigator for Canada.

"We've also seen the Correctional Services of Canada not renew contracts with some health professionals because of concerns. So there are complaints, there has been discipline and there has been administrative decisions made around contracting."

During the 2011-12 reporting period, these investigators spent 369 days in federal institutions, interviewed more than 1600 offenders and conducted 481 formal investigations.

They also received 5789 complaints from federal inmates (health care being the top category with 694 complaints, representing $11.99 \%$ of all complaints received), 18700 contacts through their toll-free number and more than 1 million hits to their website.

In addition to this, the Investigator's Use of Force team conducted 814 file reviews, reviewed 144 cases from the Corrections and Conditional Release Act involving serious bodily injury and 27 deaths in custody.

Correctional Service Canada (CSC) also internally received 361 inmate grievances related to health care in federal institutions in 2012, says CSC spokesperson Sara Parkes, but adds that this number has since decreased.

Prisoner complaints to the Colleges of Physicians and Surgeons in Canada regarding specific physicians in both provincial and federal institutions vary widely across the country, and in most cases the numbers are not recorded separately from other complaints.

Although every College that responded to questions said that they do not treat prisoner complaints differently from those of average Canadians, some provinces do not keep track of the number of prisoner complaints that they receive at all.

"Our numbers are small, maybe four per year," Dr. Ed Schollenberg, registrar for the College of Physicians and Surgeons of New Brunswick, writes in an email.

"In theory [prisoner complaints are] handled the same as any other complaint but I try and avoid most going to that process. Almost always the inmate is not so much complaining about past care but requesting help with a problem, such as access to medication, investigation, or referral. If it seems best I try and intervene with the institutional physician to see what can be done."

Saskatchewan sees about six to eight complaints a year from prisoners out of a total of 200 complaints annually,
David Poulin, a spokesperson for the College of Physicians and Surgeons of Saskatchewan writes in an email.

In Alberta, the number of prisoner complaints is not officially tracked but is estimated to be less than 20 per year out of a total of 700 to 800 complaints received annually, Kelly Eby a spokesperson for the College of Physicians and Surgeons of Alberta writes in an email.

The College of Physicians and Surgeons of Manitoba and Yukon have no concrete numbers and provided no estimations for the number of complaints received from prisoners. The Ontario college says that despite the fact that their College investigated 26 prisoner complaints in 2011 and 30 in 2012, there are unique communication barriers with prisoners that can hinder the complaint process.

"Inevitably, it does take longer to communicate with persons in custody," Kathryn Clarke, a spokesperson for the College of Physicians and Surgeons of Ontario writes in an email.

"If a person is transferred from a provincial to a federal facility, their medical record usually does not follow them to the federal institution. The unique issues in tracking down complete medical records can result in an investigation taking longer to conduct." — Adam Miller, CMAJ

CMAJ 2013. DOI:10.1503/cmaj.109-4417 